\title{
Significance of Radiofrequency Ablation for Unresectable Colorectal Cancer With Liver Metastases
}

\author{
TOMOYA TAGO $^{1}$, KENJI KATSUMATA ${ }^{1}$, RYUTARO UDOU ${ }^{1}$, KENTA KASAHARA $^{1}$, JUNICHI MAZAKI ${ }^{1}$, \\ HIROSHI KUWABARA ${ }^{1}$, MASANOBU ENOMOTO ${ }^{1}$, TETSUO ISHIZAKI ${ }^{1}$, YUICHI NAGAKAWA ${ }^{1}$, \\ KATSUTOSHI SUGIMOTO ${ }^{2}$, TAKAO ITOI ${ }^{2}$ and AKIHIKO TSUCHIDA ${ }^{1}$ \\ ${ }^{1}$ Department of Gastrointestinal and Pediatric Surgery, Tokyo Medical University, Tokyo, Japan; \\ ${ }^{2}$ Department of Gastroenterology and Hepatology, Tokyo Medical University, Tokyo, Japan
}

\begin{abstract}
Background/Aim: We aimed to investigate the prognosis of patients who received radiofrequency ablation (RFA) for liver metastases of unresectable colorectal cancer $(C R C)$. Patients and Methods: We retrospectively compared 147 patients treated for CRC liver metastases, who underwent RFA $(n=26)$, resection $(n=92)$, and chemotherapy $(n=29)$ between 2001 and 2021. Results: RFA and chemotherapy were performed for unresectable or non-operable cases, and resection was performed for suitable cases. The median overall survival (OS) was 44.9, 49.5, and 11.6 months for patients who underwent RFA, resection, and chemotherapy, respectively. RFA led to a significantly shorter OS compared to resection ( $p=0.027$ ) but to a longer OS compared to chemotherapy $(p=0.003)$. The 5-year survival rates were $34.6 \%$ and $42.4 \%$ for patients who underwent RFA and resection, respectively $(p=0.508)$. Conclusion: RFA has the potential to achieve longterm survival or radical cure, even for unresectable or nonoperable cases of CRC with liver metastasis.
\end{abstract}

Liver metastasis in colorectal cancer (CRC) is a prognostic factor; it is important to control metastasis for improved longterm prognosis. Liver metastases develop in approximately $30 \%$ of all CRC patients during their follow-up period and cause at least two-thirds of CRC deaths (1). Owing to improvements in perioperative management and surgical techniques, the 5-year survival rate increased to approximately $50 \%$, and the median overall survival (OS) increased to over 60 months for patients

This article is freely accessible online.

Correspondence to: Kenji Katsumata (ORCID: 0000-0002-48493524), Department of Gastrointestinal and Pediatric Surgery, 6-7-1 Nishisinjuku, Sinjuku-ku, Tokyo, Japan. Tel: +81 333426111, Fax: +81333426203, e-mail: k-katsu@tokyo-med.ac.jp

Key Words: Colorectal cancer, liver metastasis, radiofrequency ablation, resection, chemotherapy, prognosis. undergoing resection for liver metastases of CRC in the recent years (2). The median OS for patients with metastatic CRC was limited to approximately 8-12 months when fluorouracil and leucovorin were the only therapeutic options (3). Recently, the appearance of irinotecan, oxaliplatin, molecular-targeted drugs, and immune checkpoint inhibitors, and new concept of medication methods have improved prognosis, and the median OS has increased up to 2 years. However, it is difficult to expect a cure or obtain a long-term prognosis comparable to that of patients who can receive local treatment, such as surgery in resectable cases (4-9). Conversion surgery is currently widely accepted for unresectable liver metastases with the benefit of progress of chemotherapy. The response, resection and survival rate are closely related, and asking for opportunities of local treatment while performing systemic multidisciplinary treatment is considered to be the key to radical cure or long-term survival $(1,10,11)$.

Radiofrequency ablation (RFA) was introduced in the late 1990s as a local treatment method with minimal invasion and low morbidity. A therapeutic strategy combining RFA for chemotherapy and surgery was examined in a clinical trial for the local control of unresectable liver metastases (12). The combined use of RFA in multidisciplinary treatment is considered to further prolong the prognosis of patients following careful selection of the indication according to the treatment schedule, background factors, and lesion factors for each individual case $(13,14)$.

The objective of this study was to retrospectively investigate the clinical and oncological profiles and prognosis of patients who received multidisciplinary treatment containing RFA for liver metastases of CRC, not suitable for complete resection or is non-operable, compared with complete resection or chemotherapy, at a single institution.

\section{Patients and Methods}

Study design. This study was performed in accordance with the Declaration of Helsinki and was approved by the Research and 
Ethics Committee of Tokyo Medical University (study approval no: T2019-0054). Informed consent was obtained from all the patients. Data were collected from medical records and our database.

We retrospectively selected and analyzed data of 147 patients treated for liver metastases of CRC in the Department of Gastrointestinal and Pediatric Surgery, Tokyo Medical University between November 2001 and April 2021. The patients were divided into three groups, as follows. Twenty-six consecutive patients received multidisciplinary treatment containing chemotherapy and/or surgery and at least one RFA between September 2002 and March 2021 (RFA group: Group A). Ninety-two consecutive patients underwent hepatic resection for resectable liver metastases between September 2003 and April 2021 (resection group, Group B). Twenty-nine consecutive patients received only systemic chemotherapy for CRC with liver metastases because local treatment was not indicated during the entire period between November 2001 and May 2012 (chemotherapy group: Group C). All patients were diagnosed with liver metastases based on computed tomography (CT), magnetic resonance imaging (MRI), ultrasonography (US), or positron emission tomography (PET).

The factors related to unresectable liver metastases were defined as follows: metastatic lesions adjacent to or clearly infiltrating two or more major hepatic veins, portal bifurcation or subhepatic inferior vena cava, metastatic lesions adjacent to or clearly infiltrating the right or left branch of the portal vein and the major hepatic vein in the contralateral lobe, and remnant liver volume after resection of $40 \%$ or less of the pre-resected non-cancerous liver volume because of the number or lobe localization of the tumor. Cases other than unresectable liver metastases were defined as resectable liver metastases. Patient factors included the presence of hepatic dysfunction intolerable to hepatic resection and systemic disease that is a contraindication to general anesthesia.

RFA was performed when the case was untreatable with surgery alone, when hepatectomy could not be performed due to a comorbidity, when other distant metastases were present but liver metastasis influenced the prognosis, or when patients wished to avoid surgery. RFA was performed percutaneously under local anesthesia and sedation using US and CT or under laparotomy with general anesthesia in combination with surgery.

Group C patients were diagnosed with liver metastasis as a prognostic factor, even if there were other metastases, and received only systemic chemotherapy that included FOLFOX (5-fluorouracil, leucovorin, and oxaliplatin) at any time during their therapeutic course. All patients in this study were able to select FOLFOX and FOLFIRI (5-fluorouracil, leucovorin, and irinotecan) in any period, as well as CAPOX (capecitabine, oxaliplatin), SOX (S-1, oxaliplatin), IRIS (irinotecan, S-1), and others, depending on the case and period. Since the use of molecular-targeted drugs was permitted after domestic approval was obtained under the Japanese medical system, bevacizumab has been in use since April 2007; cetuximab, since July 2008; panitumumab, since April 2010; and ramucirumab, since May 2016. The other groups also received the same chemotherapy, as necessary, after recurrence that did not respond to local treatment.

Assessment parameters for all patients were as follows: general information [age, sex, serum carcinoembryonic antigen (CEA) and carbohydrate antigen 19-9 (CA19-9) level at diagnosis of liver metastases, primary lesion, histopathological type, distant metastases other than liver metastases, overall survival, 5-year survival rate], and information on liver metastases (synchronous/metachronous, number and maximum diameter of lesion, lobe of lesion existence, severity classification by number and size). Since both synchronous and metachronous cases were included, the start of the observation period was defined as the time of diagnosis of liver metastases. Additional parameters for Groups A and B were as follows: pathological TNM classification at the first diagnosis, with/without perioperative adjuvant chemotherapy, and number of hepatectomies. The parameters specific to Group A were as follows: total number of enforcements for RFA, total number and maximum diameter of lesions treated by RFA in the therapeutic course, approach method, and reasons for performing RFA.

Severity classification for liver metastases. Severity classification was determined at the first diagnosis of liver metastases by the combination of the number and maximum diameter of lesions. Images were evaluated using CT, MRI, and US. The classification was as follows: $\mathrm{HX}$, liver metastasis cannot be assessed; H0, no liver metastasis; H1, 1-4 metastatic tumors, all of which are $\leq 5 \mathrm{~cm}$ in maximum diameter; $\mathrm{H} 2$, not $\mathrm{H} 1$ or $\mathrm{H} 3$; and $\mathrm{H} 3$, five or more metastatic tumors, at least one of which is $>5 \mathrm{~cm}$ in maximum diameter. This system was defined by the Japanese Classification of Colorectal, Appendiceal, and Anal Carcinoma Third English Edition (15).

Statistical analysis. To assess statistical significance, univariate analyses were performed using the Fisher's exact test, Student's $t$ test, and Mann-Whitney $U$-test. Survival curves were calculated using the Kaplan-Meier method, and statistical differences in survival were identified using the log-rank test for univariate analysis and Cox proportional hazards models for multivariate analysis. Statistical analyses were performed using the IBM SPSS Statistics ver. 27 (IBM Corp, Armonk, NY, USA). Statistical significance was set at $p<0.05$.

\section{Results}

During the study period, a total of 147 patients were treated for liver metastases of CRC. There were 26 patients (17.7\%) treated with RFA, 92 patients (62.6\%) treated mainly with surgery, and 29 patients (19.7\%) treated mainly with chemotherapy. The clinicopathological characteristics of patients are shown in Table I, and survival outcomes are shown in Table II for each group. The clinical characteristics of the RFA performed for Group A are shown in Table III. Oncological analyses of OS are shown in Table IV and Table V.

Characteristics of patients. There were 26 patients in Group A, of whom 19 were men and 7 were women. The median age was 62.5 years (range $=45-83$ years). The five-year survival rate was $34.6 \%$, and the median OS was 44.9 months (range $=9.8-157.2$ months). There were 92 patients in Group B, 61 men and 31 women. The median age was 65.5 years (range $=28-87$ years). The five-year survival rate was $42.4 \%$, and the median OS was 49.5 months (range $=0.8$ 190.8 months). Group C comprised 29 patients, 22 men and 7 women. The median age was 63 years (range $=39-80$ years). The five-year survival rate was $6.9 \%$, and median OS was 11.6 months (range=2.1-77.5 months). 
Table I. Clinicopathological characteristics of the patients.

\begin{tabular}{|c|c|c|c|c|c|}
\hline & $\begin{array}{l}\text { Group A: RFA } \\
(\mathrm{n}=26)\end{array}$ & $\begin{array}{c}\text { Group B: Resection } \\
\qquad(\mathrm{n}=92)\end{array}$ & $p$-Value & $\begin{array}{l}\text { Group C: Chemotherapy } \\
\qquad(\mathrm{n}=29)\end{array}$ & $p$-Value \\
\hline Gender (male/female) & $19 / 7$ & $61 / 31$ & $0.637 *$ & $22 / 7$ & $1.000 *$ \\
\hline Age $(\text { years })^{\dagger}$ & $62.5(45-83)$ & $65.5(28-87)$ & $0.463 * * *$ & $63(39-80)$ & $0.720 * * *$ \\
\hline $\mathrm{CEA}(\mathrm{ng} / \mathrm{ml})^{\dagger}$ & $15(1.2-789)$ & $10.7(1.4-1,393)$ & $0.657 * *$ & $61(1-2,586)$ & $0.042 * *$ \\
\hline CA19-9 $(\mathrm{ng} / \mathrm{ml})^{\dagger}$ & $57.9(2.2-3,630)$ & $22.4(0.6-7,400)$ & $0.043 * *$ & $36.9(0.6-3,560)$ & $0.660 * *$ \\
\hline Primary lesion (colon/rectum) & $16 / 10$ & $63 / 29$ & $0.637 *$ & $17 / 12$ & $1.000 *$ \\
\hline Histopathological type (tub1/tub2/muc/por/ND) & $4 / 20 /-/-/ 2$ & $20 / 60 / 3 / 1 / 8$ & & $10 / 16 / 1 / 2 / 0$ & \\
\hline Other distant metastases (yes/no) & $8 / 18$ & $10 / 82$ & $0.026^{*}$ & $11 / 18$ & $0.777 *$ \\
\hline Synchronous/Metachronous & $19 / 7$ & $55 / 37$ & $0.165^{*}$ & $25 / 4$ & $0.490 *$ \\
\hline \multicolumn{6}{|l|}{ Number of metastases $\ddagger$} \\
\hline Mean & $5.8(1-19)$ & $2.4(1-11)$ & $0.000 * *$ & $6.9(1-26)$ & $0.684 * *$ \\
\hline Single/Multiple & $3 / 23$ & $47 / 45$ & 0.000 & $8 / 21$ & 0.185 \\
\hline Maximum diameter of metastases $(\mathrm{cm}) \ddagger$ & $3.9(1-8)$ & $4.0(0.3-27)$ & $0.617 * *$ & $5.6(1-27)$ & $0.376^{* *}$ \\
\hline$\leq 3 \mathrm{~cm} />3 \mathrm{~cm}$ & $14 / 12$ & $48 / 44$ & $1.000 *$ & $11 / 18$ & $0.285^{*}$ \\
\hline \multicolumn{6}{|l|}{ Location of liver metastases } \\
\hline Unilateral/bilateral & $6 / 20$ & $66 / 26$ & $0.000 *$ & $14 / 15$ & $0.091 *$ \\
\hline $\mathrm{H} 1 / \mathrm{H} 2 / \mathrm{H} 3$ & $8 / 17 / 1$ & $65 / 23 / 4$ & & $10 / 10 / 9$ & \\
\hline H1/Others & $8 / 18$ & $65 / 27$ & $0.000 *$ & $10 / 19$ & $1.000 *$ \\
\hline $\mathrm{H} 3 /$ Others & $1 / 25$ & $4 / 88$ & $1.000 *$ & $9 / 20$ & $0.013^{*}$ \\
\hline $\mathrm{p}-\mathrm{T}(1 / 2 / 3 / 4 \mathrm{a} / 4 \mathrm{~b} / \mathrm{ND})$ & $0 / 1 / 13 / 9 / 2 / 1$ & $4 / 10 / 46 / 19 / 11 / 2$ & & & \\
\hline$\leq \mathrm{T} 3 />\mathrm{T} 4 \mathrm{a}$ & $14 / 11$ & $60 / 30$ & $0.352 *$ & & \\
\hline $\mathrm{p}-\mathrm{N}(0 / 1 / 2 / 3 / \mathrm{ND})$ & $8 / 10 / 6 / 0 / 2$ & $43 / 32 / 16 / 0 / 1$ & & & \\
\hline $\mathrm{N} 0 / \mathrm{N}+$ & $8 / 16$ & 4348 & $0.255^{*}$ & & \\
\hline Perioperative adjuvant chemotherapy (yes/no) & $24 / 2$ & $75 / 17$ & $0.636^{*}$ & & \\
\hline Number of hepatectomy $(0 / 1 / 2 / 3)$ & $6 / 13 / 4 / 3$ & $0 / 79 / 11 / 2$ & & $29 / 0 / 0 / 0$ & \\
\hline$\leq 1 / \geq 2$ & $19 / 7$ & $79 / 13$ & $0.143 *$ & & \\
\hline
\end{tabular}

Data are shown as ${ }^{\dagger}$ median $/ \star$ mean and interquartile ranges. *Fisher’s exact test; **Mann-Whitney $U$-test; ***Student’s $t$-test. RFA: Radiofrequency ablation; CEA: carcinoembryonic antigen; CA19-9: carbohydrate antigen 19-9; CEA level: CA19-9 level and Number of metastases are at diagnosis of liver metastasis; ND: no data.

Table II. Survival outcome of patients for each group.

\begin{tabular}{|c|c|c|c|c|c|}
\hline & $\begin{array}{l}\text { Group A: RFA } \\
(\mathrm{n}=26)\end{array}$ & $\begin{array}{c}\text { Group B: Resection } \\
(\mathrm{n}=92)\end{array}$ & $p$-Value & $\begin{array}{l}\text { Group C: Chemotherapy } \\
\qquad(\mathrm{n}=29)\end{array}$ & $p$-Value \\
\hline Overall survival & $44.9(9.8-157.2)$ & $49.5(0.8-190.8)$ & $0.027 *$ & $11.6(2.1-77.5)$ & $0.003 *$ \\
\hline Five-year survival (yes/no) & $9 / 17$ & $39 / 53$ & $0.508 * *$ & $2 / 27$ & $0.017 * *$ \\
\hline Five-year survival rate (\%) & 34.6 & 42.4 & & 6.9 & \\
\hline
\end{tabular}

Data are shown as median and interquartile ranges. *Log-rank test; **Fisher's exact test. RFA: Radiofrequency ablation.

Comparison of Groups A and B. In Group A, the CA19-9 level was significantly higher $(p=0.043)$, the number of metastases was significantly higher $(p=0.000)$, unilateral metastases were significantly fewer $(p<0.001)$, the proportion of $\mathrm{H} 1$ grade was significantly lower $(p<0.001)$, and other distant metastases were significantly higher $(p=0.026)$ than in Group B (Table I). OS was significantly shorter in Group A $(p=0.027)$, and there was no significant difference in the 5 -year survival rate $(p=0.508)$ between the two groups (Table II, Figure 1).
Comparison of Groups $A$ and $C$. In Group A, the CEA level was significantly lower $(p=0.042)$, and the proportion of H3 grade was also significantly lower $(p=0.013)$ (Table I). OS was significantly longer $(p=0.003)$ and the 5-year survival rate was significantly higher $(p=0.017)$ in Group A than in Group C (Table II, Figure 1).

Clinical characteristics of patients treated with RFA in Group A. A total of 26 patients underwent RFA (Table III). Twentyone patients underwent RFA once, and five patients underwent 
Table III. Clinical characteristics of patients who received RFA in Group A.

\begin{tabular}{lc}
\hline Total number of enforcements & One: 21 cases \\
& Two: 5 cases \\
Total number of treated lesions & $2.8(1-6)$ \\
Maximum diameter of treated lesions & $2.5(0.5-8)$ \\
$>3 \mathrm{~cm}$ & 7 cases \\
$\leq 3 \mathrm{~cm}$ & 19 cases \\
Approach method (Percutaneous/Laparotomy) & $17 / 9$ \\
Reasons for RFA & \\
Unresectable liver metastases & 20 cases \\
Un-operable due to comorbidities & 2 cases \\
Refusal of surgery & 1 case \\
Other distant metastases & 3 cases \\
Local recurrence during the follow-up period (yes/no) & $8 / 18$ \\
\hline
\end{tabular}

Data are shown as mean and interquartile ranges. RFA: Radiofrequency ablation.

RFA twice in their therapeutic course. The total number of treated lesions was 2.8 (range=1-6). The maximum diameter of the treated lesions was $2.5 \mathrm{~cm}$ (range $=0.5-8 \mathrm{~cm}$ ); lesion in 7 cases were sized $>3 \mathrm{~cm}$, while 19 were $<3 \mathrm{~cm}$. Seventeen cases involved the percutaneous approach and nine involved laparotomy. Reasons for RFA included unresectable liver metastases in 20 cases, non-operable due to comorbidities in 2 cases, refusal of surgery in 1 case, and existence of other distant metastases in 3 cases.

Local recurrence of lesions that underwent RFA occurred in 8 of the 26 cases. Regarding local recurrence, the maximum diameter of metastases $(>3 \mathrm{~cm})$ was not a significant risk factor $(p=1.000)$ as evaluated by Fisher's exact test, and the total number of treated lesions did not reach a significant level $(p=0.120)$ to be considered as a risk factor by the Mann-Whitney $U$-test.

Comparison between the three groups for overall survival by $H$ classification. For all groups, OS was longer in the $\mathrm{H} 1$ grade than in the $\mathrm{H} 2$ grade $(p=0.014)$ and longer in the $\mathrm{H} 2$ grade than in the $\mathrm{H} 3$ grade $(p=0.007)$ (Figure 2$)$.

Oncological analysis for overall survival. Synchronous/ metachronous $(p=0.041)$, maximum diameter of metastases $(\leq 3 \mathrm{~cm}$ or $>3 \mathrm{~cm})(p=0.002), \mathrm{H} 1$ grade $(p=0.001)$, and H3 grade $(p<0.001)$ had significant differences in OS among the three groups (Table IV). The maximum diameter of metastases $(\leq 3 \mathrm{~cm}$ or $>3 \mathrm{~cm}) \quad(p=0.025), \mathrm{H} 1$ grade $(p=0.009), \mathrm{H} 3$ grade $(p=0.002)$, and pathological $\mathrm{T}$ factor $(p=0.002)$ showed significant differences in OS between Groups A and B (Table IV). No factor had a significant difference in OS within Group A alone (Table IV).

Multivariate analysis for overall survival. $\mathrm{H} 3$ grade was an independent significant risk factor for OS by multivariate analysis among the three groups [odds ratio $(\mathrm{OR})=2.335 ; 95 \%$ confidence interval $(\mathrm{CI})=1.139-4.786 ; p=0.021$; Table V]. Pathological $\mathrm{T}$ factor $(>\mathrm{T} 4 \mathrm{a}$ ) was an independent significant risk factor for OS in the multivariate analysis in Groups $\mathrm{A}$ and $\mathrm{B}(\mathrm{OR}=2.097 ; 95 \% \mathrm{CI}=1.219-3.609 ; p=0.007$; Table V).

\section{Discussion}

The objective of this study was to determine whether RFA can contribute to the prolongation of OS by controlling unresectable liver metastases as a local treatment. For nonoperable cases or those not suitable for complete resection, RFA is often performed mainly or adjunctively as a local treatment in addition to chemotherapy. Some studies, including a clinical trial, have shown that supplemental RFA indicated longer survival than chemotherapy alone (12, 14, $16,17)$. Surgery is the first choice for the treatment and long-term survival of patients with liver metastases. There are a number of retrospective studies comparing RFA and surgery, most of these studies indicate that surgery is superior to RFA in terms of the 5-year survival rate, median OS, and disease-free survival (DFS). However, in reality, it is difficult to compare these two strategies because the RFA group includes more extrahepatic disease, comorbidities, prior liver resection, and higher serum CEA levels (18-21). Local treatment, such as surgery and RFA, and systemic treatment, such as chemotherapy, serve different therapeutic purposes, as these vary in treatment target and intensity. Local treatment, which has a very strong antitumor effect for the treated area, is mainly indicated for radical cure, where the affected area is only where lesions can be recognized macroscopically by images. In contrast, systemic treatment targets tumor cells throughout the body aiming at tumor reduction and is selected for the purpose of prolongation of prognosis, adjuvant therapy, and bridging to local treatment. However, systemic treatment has a weaker antitumor effect compared to local treatment, can induce treatment resistance, and varies in terms of the therapeutic effect among individuals. It is standard to control all lesions to achieve radical cure when local treatment is used, except for palliative treatment. Similarly, resection of only the primary lesion does not prolong OS of patients with CRC with distant metastases, and it is important to control all distant lesions (22). Liver metastases will cause at least two-thirds of CRC deaths and can be a major prognostic factor. Thus, controlling liver metastases contributes to prolongation of OS even in the presence of other distant metastases (1).

Our results indicate that Group A was superior to Group C $(p=0.003)$ in terms of OS. Both groups were considered unresectable or non-operable, and nearly $50 \%$ of them had other distant metastases; therefore, the oncological background was not favorable. It is hypothesized that Group A had a longer OS than Group $\mathrm{C}$ because the local treatment 
Table IV. Oncological analysis for overall survival.

\begin{tabular}{|c|c|c|c|c|c|c|}
\hline & $\begin{array}{l}\text { Three groups } \\
\quad(\mathrm{n}=147)\end{array}$ & $p$-Value & $\begin{array}{l}\text { Group A and Group B: RFA } \\
\text { and Resection }(\mathrm{n}=118)\end{array}$ & $p$-Value & $\begin{array}{l}\text { Group A: RFA } \\
\quad(\mathrm{n}=26)\end{array}$ & $p$-Value \\
\hline Primary lesion (colon/rectum) & $96 / 51$ & 0.760 & $79 / 39$ & 0.826 & $16 / 10$ & 0.227 \\
\hline Synchronous/Metachronous & $99 / 48$ & 0.041 & $44 / 74$ & 0.236 & $19 / 7$ & 0.576 \\
\hline \multicolumn{7}{|l|}{ Number of metastases } \\
\hline Single/Multiple & $58 / 89$ & 0.205 & $50 / 68$ & 0.268 & $3 / 23$ & 0.140 \\
\hline \multicolumn{7}{|l|}{ Maximum diameter of metastases } \\
\hline$\leq 3 \mathrm{~cm} />3 \mathrm{~cm}$ & $73 / 74$ & 0.002 & $62 / 56$ & 0.025 & $14 / 12$ & 0.795 \\
\hline Location of liver metastases (unilateral/bilateral) & $86 / 61$ & 0.085 & & & $6 / 20$ & 0.318 \\
\hline $\mathrm{H} 1 / \mathrm{H} 2 / \mathrm{H} 3$ & $83 / 50 / 14$ & & & & & \\
\hline H1/Others & $83 / 64$ & 0.001 & $73 / 45$ & 0.009 & $8 / 18$ & 0.150 \\
\hline H3/Others & $14 / 133$ & 0.000 & $5 / 113$ & 0.002 & $1 / 25$ & 0.461 \\
\hline Other distant metastases (yes/no) & $29 / 118$ & 0.064 & $18 / 100$ & 0.097 & $8 / 18$ & 0.648 \\
\hline \multicolumn{7}{|l|}{$\mathrm{p}-\mathrm{T}$ ( 3 cases are no data) } \\
\hline$\leq \mathrm{T} 3 />\mathrm{T} 4 \mathrm{a}$ & & & $74 / 41$ & 0.002 & $14 / 11$ & 0.478 \\
\hline \multicolumn{7}{|l|}{$\mathrm{p}-\mathrm{N}$ ( 3 cases are no data) } \\
\hline $\mathrm{N} 0 / \mathrm{N}+$ & & & $51 / 64$ & 0.113 & $8 / 16$ & 0.633 \\
\hline Perioperative adjuvant chemotherapy (yes/no) & & & $99 / 19$ & 0.172 & $24 / 2$ & 0.434 \\
\hline \multicolumn{7}{|l|}{ Number of hepatectomy } \\
\hline$\leq 1 / \geq 2$ & & & $98 / 20$ & 0.173 & $19 / 7$ & 0.137 \\
\hline
\end{tabular}

Data were analyzed by Log-rank test. RFA: Radiofrequency ablation.

Table V. Multivariate analysis for overall survival.

\begin{tabular}{|c|c|c|c|c|c|c|c|}
\hline \multirow[b]{2}{*}{ Covariate } & & \multicolumn{3}{|c|}{$\begin{array}{l}\text { Three groups } \\
\quad(\mathrm{n}=147)\end{array}$} & \multicolumn{3}{|c|}{$\begin{array}{c}\text { Group A and Group B: } \\
\text { RFA and Resection }(n=118)\end{array}$} \\
\hline & & Odds & $95 \% \mathrm{CI}$ & $p$-Value & Odds & $95 \% \mathrm{CI}$ & $p$-Value \\
\hline \multirow[t]{2}{*}{ Synchronous/Metachronous } & Meta & 1 & & & & & \\
\hline & Syn & 1.399 & $0.833-2.349$ & 0.204 & & & \\
\hline \multirow[t]{2}{*}{ Maximum diameter of metastases } & $\leq 3 \mathrm{~cm}$ & 1 & & & 1 & & \\
\hline & $>3 \mathrm{~cm}$ & 1.443 & $0.868-2.397$ & 0.157 & 1.125 & $0.624-2.029$ & 0.695 \\
\hline \multirow[t]{4}{*}{$\mathrm{H} 1 / \mathrm{H} 2 / \mathrm{H} 3$} & $\mathrm{H} 1$ & 1 & & & 1 & & \\
\hline & Others & 1.452 & $0.868-2.431$ & 0.156 & 1.623 & $0.922-2.857$ & 0.093 \\
\hline & Others & 1 & & & 1 & & \\
\hline & $\mathrm{H} 3$ & 2.335 & $1.139-4.786$ & 0.021 & 2.234 & $0.752-6.635$ & 0.148 \\
\hline \multirow[t]{2}{*}{ p-T } & $\leq \mathrm{T} 3$ & & & & 1 & & \\
\hline & $>\mathrm{T} 4 \mathrm{a}$ & & & & 2.097 & $1.219-3.609$ & 0.007 \\
\hline
\end{tabular}

Data were analyzed by Cox proportional hazards models. CI: Confidence interval; Meta: metachronous; Syn: synchronous.

could be expanded and adapted by combining RFA, and obtaining a cure or controlling liver metastases by local treatment may contribute to the prolongation of OS. Our results also showed that Group B was superior to Group A $(p=0.027)$ in terms of OS. However, because cancer was unresectable or non-operable, Group A patients demonstrated significantly higher CA19-9 levels $(p=0.043)$, mean number of metastases $(p<0.001)$, single/multiple number of metastases $(p=0.000)$, bilateral location of lesion $(p=0.000)$, and other distant metastases $(p=0.026)$. Additionally, Group A had a significantly lower H1 grade $(p<0.001)$. The oncological background of Group A was not similar to that in other reports, and there are no clinical trials or reports comparing patients based on a uniform background. The 5year survival rate was not significantly different $(p=0.508)$ between Groups A and B; therefore, the result seemed to be meaningful, considering the difference in oncological background.

We used the $\mathrm{H}$ classification and found a significant difference in OS according to each grade between the three groups (Figure 2). In particular, there was a significant difference in OS by $\mathrm{H} 1$ or $\mathrm{H} 3$ between Groups A and B (Table 


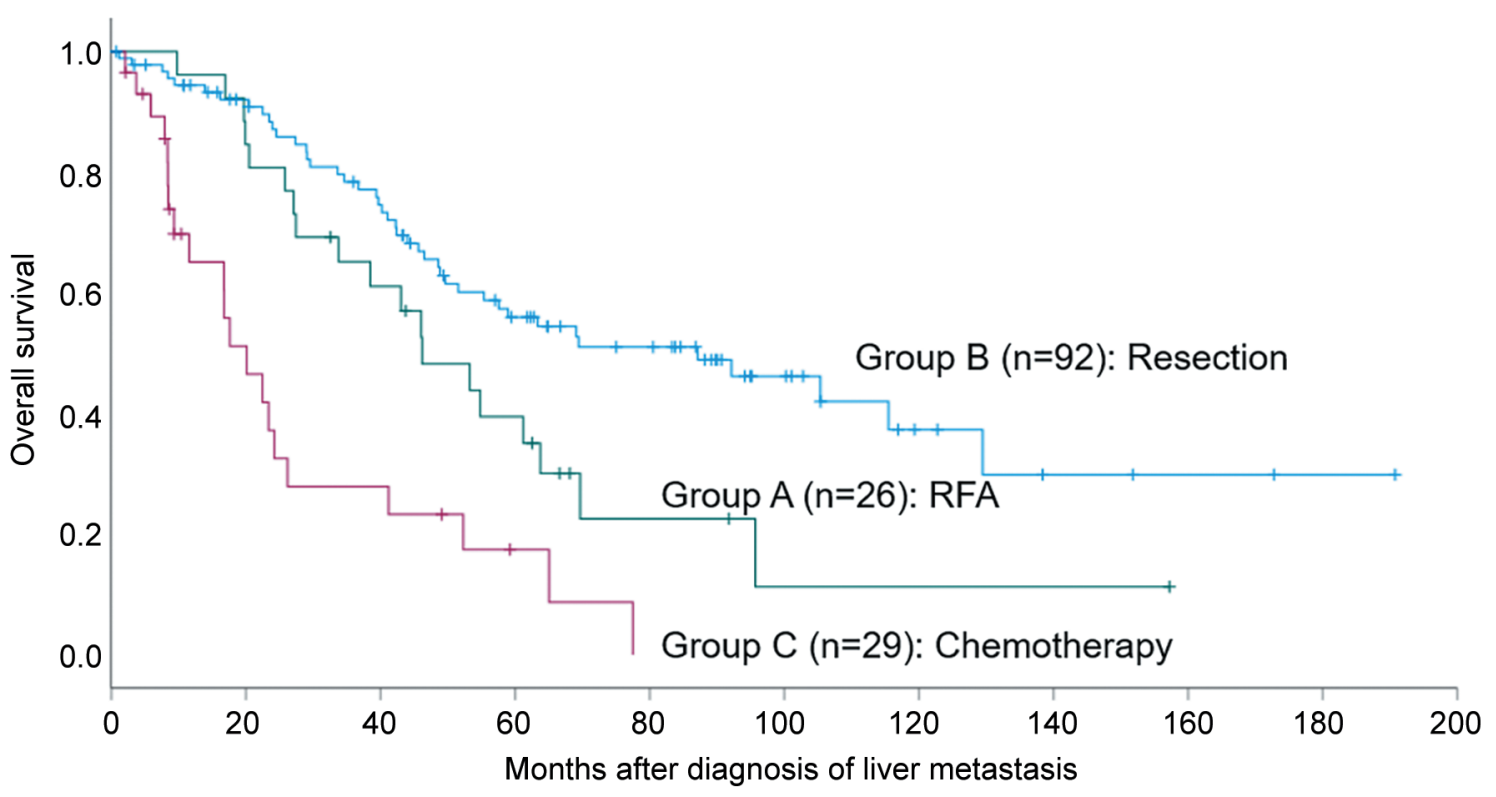

Figure 1. Overall survival of patients treated with resection (blue), RFA (green), and chemotherapy (red).

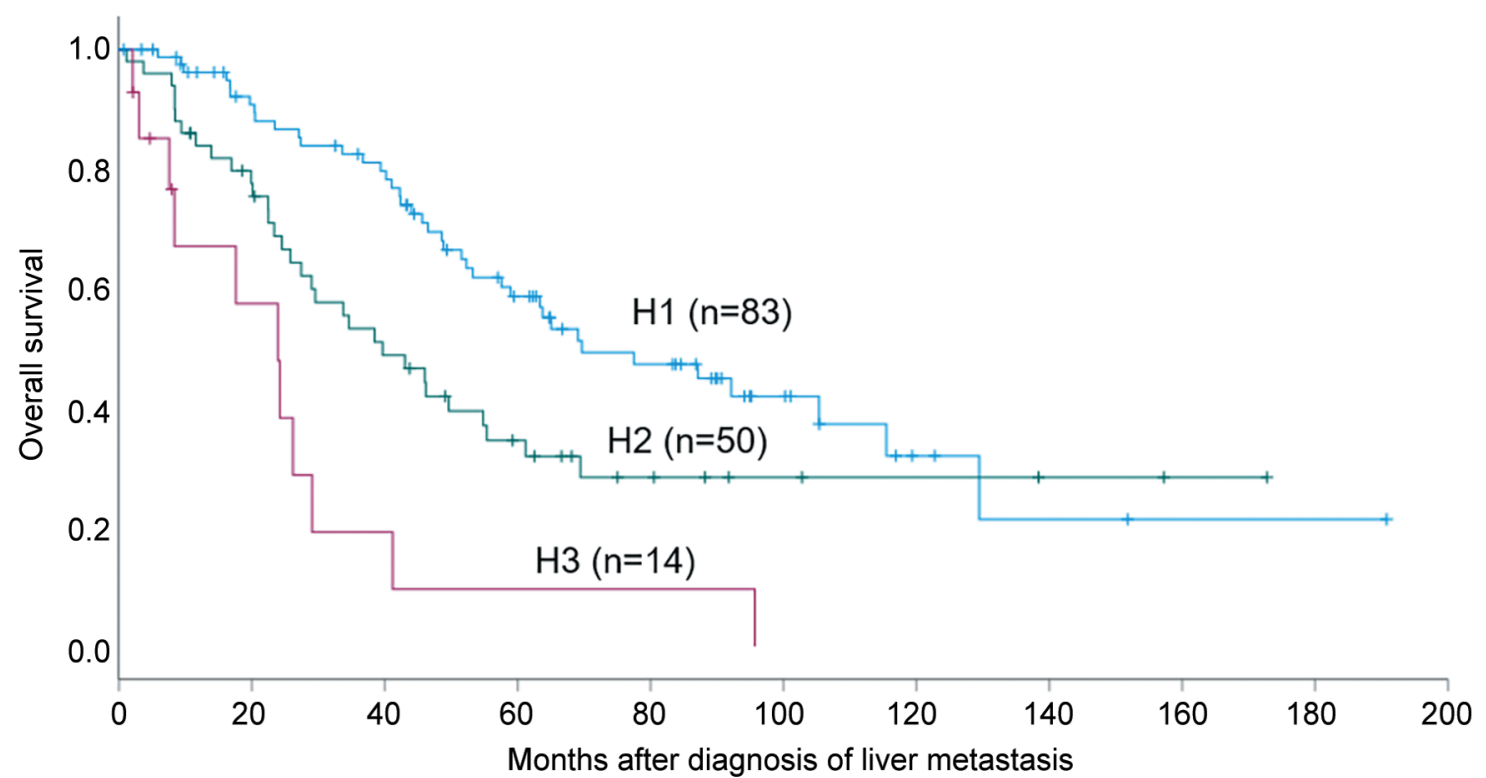

Figure 2. Overall survival of patients treated with $\mathrm{H1}$ grade (blue), $\mathrm{H} 2$ grade (green), and $\mathrm{H} 3$ grade (red).

IV). In this study, H3 grade $(p=0.021)$ was found to be a significant independent prognostic factor upon multivariate analysis among the three groups. H1 grade between the three groups $(p=0.156)$, and $\mathrm{H} 1(p=0.093)$ and H3 $(p=0.148)$ grades in Groups A and B were considered as prognostic factors (Table IV), but these did not reach a significant level in the multivariate analysis (Table V). Since liver metastasis has a prominent effect on prognosis, it is important to treat it aggressively. Selecting local treatment rather than chemotherapy as much as possible may improve the prognosis.

The T4 factor, established as a TNM classification, was indicated as an independent prognostic factor by multivariate analysis in Groups A and B, in cases where local treatment was performed. Metachronous/synchronous and maximum 
diameter of metastases $(>3 \mathrm{~cm})$ were identified as prognostic factors by univariate analysis. Therefore, these factors were also not considered important. Unfortunately, none of the factors reached a significant level in Group A alone by univariate analysis, and it was not possible to consider adaptive selection for RFA.

Almost 30 years have passed since the introduction of RFA, and data have been accumulated steadily regarding CRC liver metastasis and not only hepatocellular carcinoma, which is in high demand for RFA. Cirimbei reported in a retrospective study regarding immediate and long-term results of RFA for unresectable or non-operable liver metastasis of CRC, and indicated that RFA is safe, has low rates of local relapses and recurrences, and acceptable survival rates (23). As a minimally invasive local treatment, the main roles of RFA for unresectable or non-operable cases of CRC with liver metastasis are to assist as a complementary local treatment and to control liver metastases in cases with a defined prognosis due to liver metastases. In this study, RFA was performed as complementary method in 23 cases but also to control liver metastasis despite of other distant metastasis in 3 cases (Table III). Compared to surgery, RFA is a minimally invasive and repeatable local treatment that aims for radical cure and can easily reach multiple bilateral lobes or deep lesions. The disadvantages are the high local recurrence rate and limited size of the adaptive lesions (21). In our study, local recurrence was observed in $8(30.8 \%)$ of the 26 RFA cases. Analyzing the cause of local recurrence, the maximum diameter of metastases $(>3 \mathrm{~cm})$ was not considered a risk factor $(p=1.000)$, while the total number of treated lesions could be considered a risk factor, although it did not reach significance $(p=0.120)$. The association between the risk, chemotherapy, and disease status before and after the treatment period could not be evaluated. Based on our observations, local control can be achieved by combining surgery with RFA. In addition, RFA can be useful when requiring an immediate introduction of chemotherapy as soon as possible due to other distant metastases, in those with liver metastases that recurred early after resection, in non-operable cases due to comorbidities, and when patients refuse to undergo surgery.

In recent decades, the prognosis for unresectable advanced/recurrent CRC increased significantly with the development of chemotherapy, but it is still far below that of resectable cases $(12,13)$. In a systematic review and metaanalysis regarding treatment of CRC liver metastases, RFA plus partial hepatectomy $(\mathrm{PH})$ for patients with unresectable disease resulted in OS and DFS comparable to those of $\mathrm{PH}$ alone for patients with resectable disease (24). Furthermore, RFA can provide a survival comparable to or close to that of surgical candidates in patients with unresectable disease who only have palliative chemotherapy as a treatment option. In this study, Group A had significantly better OS and 5-year survival rates than Group C. Group A had no significant difference in the 5-year survival rate compared to Group B. From the above, it was suggested that even in cases that are unresectable or non-operable, it is possible to obtain a radical cure or a long prognosis equal to or close to resectable cases by successfully using RFA. Currently, a phase III singleblind prospective randomized controlled trial is underway to prove non-inferiority of thermal ablation compared to hepatic resection (25). Depending on the results of this trial, it is quite possible that the adaptation of RFA for CRC liver metastasis is going to be expanded and established.

This study has some limitations owing to its retrospective design. The study had a small sample size, selection bias due to single-center, no analysis of chemotherapy for details or cause of death, and OS was the only primary endpoint.

\section{Conclusion}

RFA is a valid option as a minimally invasive treatment to broaden the covering area of local treatment. However, the first choice is surgery, and RFA should be avoided if not considered enough. Even when treatment is not suitable for complete resection or non-operable liver metastases, it is important to perform multidisciplinary treatment by selecting an appropriate treatment method at an appropriate time considering the degree of progression, disease state, patient background, ability to receive treatment to prolong the prognosis, or have a radical cure.

\section{Conflicts of Interest}

All Authors declare no conflicts of interest or competing financial interests for this article.

\section{Authors' Contributions}

Tomoya Tago wrote the manuscript. Kenji Katsumata, Yuichi Nagakawa, Katsutoshi Sugimoto, Takao Itoi and Akihiko Tsuchida critically reviewed and revised the manuscript. Tomoya Tago, Ryutaro Udou, Kenta Kasahara, Junichi Mazaki, Hiroshi Kuwabara, Masanobu Enomoto and Tetsuo Ishizaki performed the literature search and data analysis. All other coauthors discussed the content of the manuscript. All Authors read and approved the final manuscript.

\section{References}

1 Kopetz S, Chang GJ, Overman MJ, Eng C, Sargent DJ, Larson DW, Grothey A, Vauthey JN, Nagorney DM and McWilliams RR: Improved survival in metastatic colorectal cancer is associated with adoption of hepatic resection and improved chemotherapy. J Clin Oncol 27(22): 3677-3683, 2009. PMID: 19470929. DOI: $10.1200 / J C O .2008 .20 .5278$

2 House MG, Ito H, Gönen M, Fong Y, Allen PJ, DeMatteo RP, Brennan MF, Blumgart LH, Jarnagin WR and D'Angelica MI: 
Survival after hepatic resection for metastatic colorectal cancer: trends in outcomes for 1,600 patients during two decades at a single institution. J Am Coll Surg 210(5): 744-52, 752-5, 2010. PMID: 20421043. DOI: 10.1016/j.jamcollsurg.2009.12.040

3 Meta-analysis Group In Cancer, Piedbois P, Rougier P, Buyse M, Pignon J, Ryan L, Hansen R, Zee B, Weinerman B, Pater J, Leichman C, Macdonald J, Benedetti J, Lokich J, Fryer J, Brufman G, Isacson R, Laplanche A and Levy E: Efficacy of intravenous continuous infusion of fluorouracil compared with bolus administration in advanced colorectal cancer. J Clin Oncol 16(1): 301-308, 1998. PMID: 9440757. DOI: 10.1200/JCO.1998.16.1.301

4 Tournigand C, André T, Achille E, Lledo G, Flesh M, MeryMignard D, Quinaux E, Couteau C, Buyse M, Ganem G, Landi B, Colin P, Louvet C and de Gramont A: FOLFIRI followed by FOLFOX6 or the reverse sequence in advanced colorectal cancer: a randomized GERCOR study. J Clin Oncol 22(2): 229237, 2004. PMID: 14657227. DOI: 10.1200/JCO.2004.05.113

5 Grothey A, Sugrue MM, Purdie DM, Dong W, Sargent D, Hedrick E and Kozloff M: Bevacizumab beyond first progression is associated with prolonged overall survival in metastatic colorectal cancer: results from a large observational cohort study (BRiTE). J Clin Oncol 26(33): 5326-5334, 2008. PMID: 18854571. DOI: 10.1200/JCO.2008.16.3212

6 Karapetis CS, Khambata-Ford S, Jonker DJ, O'Callaghan CJ, Tu D, Tebbutt NC, Simes RJ, Chalchal H, Shapiro JD, Robitaille S, Price TJ, Shepherd L, Au HJ, Langer C, Moore MJ and Zalcberg JR: K-ras mutations and benefit from cetuximab in advanced colorectal cancer. N Engl J Med 359(17): 1757-1765, 2008. PMID: 18946061. DOI: 10.1056/NEJMoa0804385

7 Amado RG, Wolf M, Peeters M, Van Cutsem E, Siena S, Freeman DJ, Juan T, Sikorski R, Suggs S, Radinsky R, Patterson SD and Chang DD: Wild-type KRAS is required for panitumumab efficacy in patients with metastatic colorectal cancer. J Clin Oncol 26(10): 1626-1634, 2008. PMID: 18316791. DOI: 10.1200/JCO.2007.14.7116

8 Grothey A, Sargent D, Goldberg RM and Schmoll HJ: Survival of patients with advanced colorectal cancer improves with the availability of fluorouracil-leucovorin, irinotecan, and oxaliplatin in the course of treatment. J Clin Oncol 22(7): 1209-1214, 2004. PMID: 15051767. DOI: 10.1200/JCO.2004.11.037

9 Tejpar S, Stintzing S, Ciardiello F, Tabernero J, Van Cutsem E, Beier F, Esser R, Lenz HJ and Heinemann V: Prognostic and predictive relevance of primary tumor location in patients with RAS wild-type metastatic colorectal cancer: Retrospective analyses of the CRYSTAL and FIRE-3 trials. JAMA Oncol 3(2): 194-201, 2017. PMID: 27722750. DOI: 10.1001/jamaoncol.2016.3797

10 Folprecht G, Grothey A, Alberts S, Raab HR and Köhne CH: Neoadjuvant treatment of unresectable colorectal liver metastases: correlation between tumour response and resection rates. Ann Oncol 16(8): 1311-1319, 2005. PMID: 15870084. DOI: $10.1093 /$ annonc/mdi246

11 Adam R, Wicherts DA, de Haas RJ, Ciacio O, Lévi F, Paule B, Ducreux M, Azoulay D, Bismuth $\mathrm{H}$ and Castaing D: Patients with initially unresectable colorectal liver metastases: is there a possibility of cure? J Clin Oncol 27(11): 1829-1835, 2009. PMID: 19273699. DOI: 10.1200/JCO.2008.19.9273

12 Ruers T, Punt C, Van Coevorden F, Pierie JPEN, Borel-Rinkes I, Ledermann JA, Poston G, Bechstein W, Lentz MA, Mauer M, Van Cutsem E, Lutz MP, Nordlinger B, EORTC Gastro-Intestinal Tract Cancer Group and Arbeitsgruppe Lebermetastasen und - tumoren in der Chirurgischen Arbeitsgemeinschaft Onkologie (ALM-CAO) and the National Cancer Research Institute Colorectal Clinical Study Group (NCRI CCSG): Radiofrequency ablation combined with systemic treatment versus systemic treatment alone in patients with non-resectable colorectal liver metastases: a randomized EORTC Intergroup phase II study (EORTC 40004). Ann Oncol 23(10): 2619-2626, 2012. PMID: 22431703. DOI: 10.1093/annonc/ mds053

13 Berber E, Tsinberg M, Tellioglu G, Simpfendorfer $\mathrm{CH}$ and Siperstein AE: Resection versus laparoscopic radiofrequency thermal ablation of solitary colorectal liver metastasis. J Gastrointest Surg 12(11): 1967-1972, 2008. PMID: 18688683. DOI: $10.1007 / \mathrm{s} 11605-008-0622-8$

14 Machi J, Oishi AJ, Sumida K, Sakamoto K, Furumoto NL, Oishi $\mathrm{RH}$ and Kylstra JW: Long-term outcome of radiofrequency ablation for unresectable liver metastases from colorectal cancer: evaluation of prognostic factors and effectiveness in first- and second-line management. Cancer J 12(4): 318-326, 2006. PMID: 16925977. DOI: 10.1097/00130404-200607000-00011

15 Japanese Society for Cancer of the Colon and Rectum: Japanese classification of colorectal, appendiceal, and anal carcinoma: the 3d English edition [Secondary Publication]. J Anus Rectum Colon 3(4): 175-195, 2019. PMID: 31768468. DOI: 10.23922/ jarc.2019-018

16 Berber E, Pelley R and Siperstein AE: Predictors of survival after radiofrequency thermal ablation of colorectal cancer metastases to the liver: a prospective study. J Clin Oncol 23(7): 1358-1364, 2005. PMID: 15684312. DOI: 10.1200/JCO.2005.12.039

17 Siperstein AE, Berber E, Ballem N and Parikh RT: Survival after radiofrequency ablation of colorectal liver metastases: 10-year experience. Ann Surg 246(4): 559-65; discussion 565-7, 2007. PMID: 17893492. DOI: 10.1097/SLA.0b013e318155a7b6

18 White RR, Avital I, Sofocleous CT, Brown KT, Brody LA, Covey A, Getrajdman GI, Jarnagin WR, Dematteo RP, Fong Y, Blumgart LH and D'Angelica M: Rates and patterns of recurrence for percutaneous radiofrequency ablation and open wedge resection for solitary colorectal liver metastasis. J Gastrointest Surg 11(3): 256-263, 2007. PMID: 17458595. DOI: 10.1007/s11605-007-0100-8

19 Aloia TA, Vauthey JN, Loyer EM, Ribero D, Pawlik TM, Wei SH, Curley SA, Zorzi D and Abdalla EK: Solitary colorectal liver metastasis: resection determines outcome. Arch Surg 141(5): 460-6; discussion 466-7, 2006. PMID: 16702517. DOI: 10.1001/archsurg.141.5.460

20 Oshowo A, Gillams A, Harrison E, Lees WR and Taylor I: Comparison of resection and radiofrequency ablation for treatment of solitary colorectal liver metastases. Br J Surg 90(10): 1240-1243, 2003. PMID: 14515293. DOI: 10.1002/ bjs. 4264

21 Park IJ, Kim HC, Yu CS, Kim PN, Won HJ and Kim JC: Radiofrequency ablation for metachronous liver metastasis from colorectal cancer after curative surgery. Ann Surg Oncol 15(1): 227-232, 2008. PMID: 17882491. DOI: 10.1245/s10434-0079625-z

22 Kanemitsu Y, Shitara K, Mizusawa J, Hamaguchi T, Shida D, Komori K, Ikeda S, Ojima H, Ike H, Shiomi A, Watanabe J, Takii Y, Yamaguchi T, Katsumata K, Ito M, Okuda J, Hyakudomi R, Shimada Y, Katayama H, Fukuda H and JCOG Colorectal Cancer Study Group: Primary tumor resection plus chemotherapy versus chemotherapy alone for colorectal cancer 
patients with asymptomatic, synchronous unresectable metastases (JCOG1007; iPACS): A randomized clinical trial. J Clin Oncol 39(10): 1098-1107, 2021. PMID: 33560877. DOI: 10.1200/JCO.20.02447

23 Cirimbei C, Rotaru V, Chitoran E, Pavaleanu O and Cirimbei SE: Immediate and long-term results of radiofrequency ablation for colorectal liver metastases. Anticancer Res 37(11): 64896494, 2017. PMID: 29061837. DOI: 10.21873/anticanres.12105

24 Meijerink MR, Puijk RS, van Tilborg AAJM, Henningsen KH, Fernandez LG, Neyt M, Heymans J, Frankema JS, de Jong KP, Richel DJ, Prevoo W and Vlayen J: Radiofrequency and microwave ablation compared to systemic chemotherapy and to partial hepatectomy in the treatment of colorectal liver metastases: A systematic review and meta-analysis. Cardiovasc Intervent Radiol 41(8): 1189-1204, 2018. PMID: 29666906. DOI: $10.1007 / \mathrm{s} 00270-018-1959-3$
25 Puijk RS, Ruarus AH, Vroomen LGPH, van Tilborg AAJM, Scheffer HJ, Nielsen K, de Jong MC, de Vries JJJ, Zonderhuis BM, Eker HH, Kazemier G, Verheul H, van der Meijs BB, van Dam L, Sorgedrager N, Coupé VMH, van den Tol PMP, Meijerink MR and COLLISION Trial Group: Colorectal liver metastases: surgery versus thermal ablation (COLLISION) - a phase III single-blind prospective randomized controlled trial. BMC Cancer 18(1): 821, 2018. PMID: 30111304. DOI: $10.1186 / \mathrm{s} 12885-018-4716-8$
Received August 31, 2021

Revised October 18, 2021

Accepted October 20, 2021 